VOLUME 73

(Whole No. 707)
NUMBER 2

MARCH, 1967

\title{
BULLETIN of the
}

\section{American Mathematical Society}

\author{
Edited by \\ FELIX BROWDER M. H. PROTTER \\ MURRAY GERSTENHABER
}

Published by the American Mathematical Society

PROVIDENCE, RHODE ISLAND 


\section{AMERICAN MATHEMATICAL SOCIETY}

General Office: P.O. Box 6248, Providence, Rhode Island 02904

Executive Director: G. L. Walker

Editorial Offices: P.O. Box 6248, Providence, Rhode Island 02904

Executive Editor Mathematical Reviews: Sterling K. Berberian

Editor Translation Projects: S. H. Gould

Officers and Editors:

President: C. B. Morrey, Department of Mathematics, University of California, Berkeley, California 94720.

Ex-President: A. A. Albert, Eckhart Hall, University of Chicago, Chicago, Illinois 60637.

Secretary: Everett Pitcher, Department of Mathematics, Lehigh University, Bethlehem, Pennsylvania 18015.

Associate Secretaries:

Professor P. T. Bateman, Department of Mathematics, University of Illinois, Urbana, Illinois 61803 .

Professor Herbert Federer, Department of Mathematics, Brown University, Providence, Rhode Island 02912.

Professor O. G. Harrold, Department of Mathematics, Florida State University, Tallahassee, Florida 32306.

Professor R. S. Pierce, Department of Mathematics, University of Washington, Seattle, Washington 98105.

Treasurer: Professor W. T. Martin, Department of Mathematics, Massachusetts Institute of Technology, Cambridge, Massachusetts 02139.

Managing Editor of the Bulletin: Professor Felix Browder, Department of Mathematics, University of Chicago, Chicago, Illinois 60637.

Managing Editor of the Proceedings: Professor Maurice Heins, Department of Mathematics, University of Illinois, Urbana, Illinois.

Managing Editor of the Transactions: Professor Dana Scott, Department of Mathematics, Stanford University, Stanford, California 94305.

Chairman, Mathematical Reviews Editorial Committee: Professor H. A. Antosiewicz, Department of Mathematics, University of Southern California, Los Angeles, California.

Chairman, Colloquium Editorial Committee: Professor Norman Steenrod, Fine Hall, Princeton University, Princeton, New Jersey 08540.

Chairman, Mathematial Surveys Committee: P. E. Conner, Cabell Hall, University of Virginia, Charlottesville, Virginia 22901.

Chairman, Mathematics of Computation Editorial Committee: Professor Eugene Isaacson, University Computing Center, Courant Institute of Mathematical Sciences, New York University, New York, New York 10012.

Representatives of the Society on the Board of Editors of the American Journal of Mathematics:

Professor Stephen Smale, Department of Mathematics, University of California, Berkeley, California 94720 .

Professor G. D. Mostow, Department of Mathematics, Yale University, New Haven, Connecticut 06520.

The annual dues of members of the Society (see this Bulletin, November, 1964, pp. 837-838) are payable to the American Mathematical Society, P.O. Box 6248, Providence, Rhode Island 02904.

The Bulletin of the American Mathematical Society is published bimonthly, in January, March, May, July, September, and November. Price per annual volume is $\$ 12.00$. Subscriptions, orders for back numbers, and inquiries in regard to nondelivery of current numbers should be addressed to the American Mathematical Society, P.O. Box 6248, Providence, Rhode Island 02904.

Second-class postage paid at Providence, Rhode Island and additional mailing offices. Acceptance for mailing at the special rate of postage provided for in the act of February 28, 1925, embodied in paragraph 4, Section 538, P. L. and R., authorized May $9,1935$.

Copyright (c) American Mathematical Society 1967

Printed in the United States of America 